\title{
PODODERMATITE EM ELEFANTE-ASIÁTICO (Elephas maximus LINNAEUS, 1758), MANTIDO SOB CUIDADOS HUMANOS
}

\author{
Rodrigo Hidalgo Friciello Teixeira ${ }^{1,2,3}$ \\ Ronnie Von Mateus Ferereira ${ }^{2}$ \\ Lanna Torrezan ${ }^{1}$ \\ Natalia Todesco ${ }^{1}$ \\ André Luiz Mota da Costa ${ }^{1}$
}

\begin{abstract}
RESUMO
O elefante é um dos maiores mamíferos terrestres, eles são carismáticos e bastante populares em jardins zoológicos. Um exemplar de elefante asiático (Elephas maximus), fêmea, adulta, mantido sob cuidados humanos, com idade aproximada de 60 anos, pesando aproximadamente três toneladas, apresentava claudicação dos membros locomotores, relutância em se movimentar e com histórico de pododermatite em membros anteriores e posteriores. Foram observadas lesões na planta da pata com presença de secreção purulenta, hiperqueratose, erosões e áreas de necrose. Com auxílio de swabs estéreis, amostras das lesões foram enviadas ao laboratório para cultura e antibiograma. O resultado laboratorial apontou o crescimento bacteriano de Klebsiella $s p$ e Citrobacter $s p$. O antibiograma revelou sensibilidade para os antiobióticos: amoxicilina e ácido clavulânico, cefalexina, enrofloxacina, gentamicina, neomicina e sulfametoxazol- trimetoprim.
\end{abstract}

Palavras chaves: animal selvagem, infecção podal, bactérias, antibiograma

\begin{abstract}
The elephant is one of the largest land mammals, they are charismatic and quite popular in zoos. An Asian elephant (Elephas maximus), adult female kept in human care, aged approximately 60 years, weighing approximately three tons, was presented limping of the forelimbs members with reluctance to move around and with a history of pododermatitis. Lesions were observed in the foot sole with the presence of purulent secretion, living tissue with areas of necrosis. With the aid of sterile swabbs, samples of the lesions were sent to the laboratory for culture and antibiogram. The laboratory result showed the bacterial growth of Klebsiella sp and Citrobacter sp. The antibiogram revealed sensitivity to the antibiotics: amoxicillin and clavulonic acid, cephalexin, enrofloxacin, gentamicin, neomycin and sulfamethoxazole-trimethoprim.
\end{abstract}

Keywords: wild animal, foot infection, bacteria, antibiogram

\section{RESUMEN}

El elefante es uno de los mamíferos terrestres más grandes, ellos son carismáticos y bastante populares en zoológicos. Una elefante asiática hembra adulta (Elephas maximus), mantenida

\footnotetext{
${ }^{1}$ Zoológico Municipal de Sorocaba, Sorocaba, SP. rhftzoo@hotmail.com

${ }^{2}$ Universidade de Sorocaba, Sorocaba, SP.

${ }^{3}$ Programa de Pós Graduação em Animais Selvagens, Faculdade de Medicina Veterinária e Zootecnia (FMVZ) da Universidade Estadual Paulista "Júlio de Mesquita Filho" (UNESP) - Campus de Botucatu, Botucatu, SP.
} 
en cuidado humano, de aproximadamente 60 años, con un peso aproximado de tres toneladas, presentaba cojera de los miembros anteriores con pereza o desgana para moverse por el recinto y con antecedentes de pododermatitis en miembros anteriores. Se observaron lesiones en la planta de la pata anterior con presencia de secreción purulenta, tejido vivo con áreas de necrosis. Con la ayuda de hisopos estériles, se enviaron muestras de las lesiones al laboratorio para cultivo y antiobiograma. El resultado de laboratorio mostró el crecimiento bacteriano de Klebsiella sp y Citrobacter sp. El antiobiograma reveló sensibilidad a los antibióticos: amoxicilina y ácido clavulónico, cefalexina, enrofloxacina, gentamicina, neomicina y sulfametoxazol- trimetoprima.

Palabras clave: animal salvaje, infección de pata, bacterias y antibiograma.

\section{INTRODUÇÃO}

Os elefantes são os maiores mamíferos terrestres, com duas espécies, elefante africano (Loxodonta africana) e elefante asiático (Elaphas maximus), pertencem à ordem Proboscidae e família elephantidae. O elefante indiano pesa entre 3 a 4 toneladas, é menor do que a espécie africana, porém é mais representado em zoológicos ao redor do mundo. No Brasil, segundo a Associação de Zoológicos e Aquários do Brasil (AZAB), existem aproximadamente 20 indivíduos de elefantes asiáticos em Zoológicos (1). A espécie está classificada como Ameaçada (EN), segundo a União Internacional para Conservação da Natureza (IUCN) devido à redução da população nas últimas três gerações. As principais ameaças são a redução da área natural, perda da qualidade do habitat e populações altamente fragmentadas. Os elefantes asiáticos ocupavam uma extensa área do continente asiático, mas a população foi reduzida drasticamente, e atualmente ainda ocorrem em populações naturais e isoladas em 13 países do sudeste asiático: Bangladesh, Butão, Índia, Nepal, Sri Lanka, Camboja, China, Indonésia, Laos, Malásia, Myanmar, Tailândia e Vietnã (2).

Problemas podais e complicações fisiológicas em membros locomotores de elefantes são apontados mundialmente como os principais problemas veterinários desta espécie, mantidas sob cuidados humanos em Zoológicos e Centro de Resgates. Entre 67,4 \% e 80,3\% dos animais "ex situ", mantidos em zoológicos da Europa e Estados Unidos da América, apresentam processos patológicos em unhas, solas e tecidos interdigitais (3-6).

Existe uma maior prevalência, discreta dos problemas podais, em elefantes asiáticos quando comparados a elefantes africanos em zoológicos, isso pode ser explicado pelo fato da espécie viver em ambientes naturalmente úmidos e superfícies inundáveis (7). Outro fator importante está relacionado aos produtos de limpeza utilizados nos recintos, associado a substratos inadequados, excessivamente ásperos e duros (8).

As bactérias da família Enterobacteriaceae constituem o maior e mais heterogêneo grupo de patógenos gram-negativos de importância médica. Possuem a forma de bacilos, medindo em média entre um e cinco micrômeros, são anaeróbicos facultativos, fermentadores de glicose, e oxidase negativos, sendo algumas espécies móveis e outras imóveis (9). As enterobactérias são encontradas no solo e em meio aquático em ambientes naturais (10). Esse grupo de bactérias possui resistência natural ou adquirida a antibióticos e desenvolve uma enorme variedade de padrões de resistência natural, adquirindo genes ligados à resistência de bactérias da própria espécie ou de espécies e gêneros diferentes, complicando ou anulando o efeito dos tratamentos das infeções (11).

O presente relato descreve a identificação do agente microbiano causador de lesões podais, e a sensibilidade de medicamentos antibióticos por meio de antibiograma em um exemplar de elefante asiático mantido sob cuidados humanos em um Zoológico.

Teixeira RHF. Pododermatite em elefante-asiático (Elephas maximus Linnaeus, 1758), mantido sob cuidados humanos Vet. e Zootec. 2021 ; v28: 001-005. 


\section{RELATO DE CASO}

Um exemplar de elefante asiático (Elephas maximus), fêmea, adulta, mantido sob cuidados humanos, com idade aproximada de 60 anos e pesando aproximadamente três toneladas, apresentava claudicação dos membros anteriores com relutância em se movimentar pelo recinto e com histórico de pododermatite em membros anteriores e posteriores. Por meio de condicionamento e com auxílio do tratador de animais, foram observadas lesões na planta da pata com presença de secreção purulenta, tecido vivo e áreas de necrose em ambas as patas. Aproveitando o manejo do animal foi coletado material biológico das lesões por meio de swabs estéreis e encaminhado ao laboratório para exames de cultura e antibiograma e na sequência realizado curativo local (figura 1).

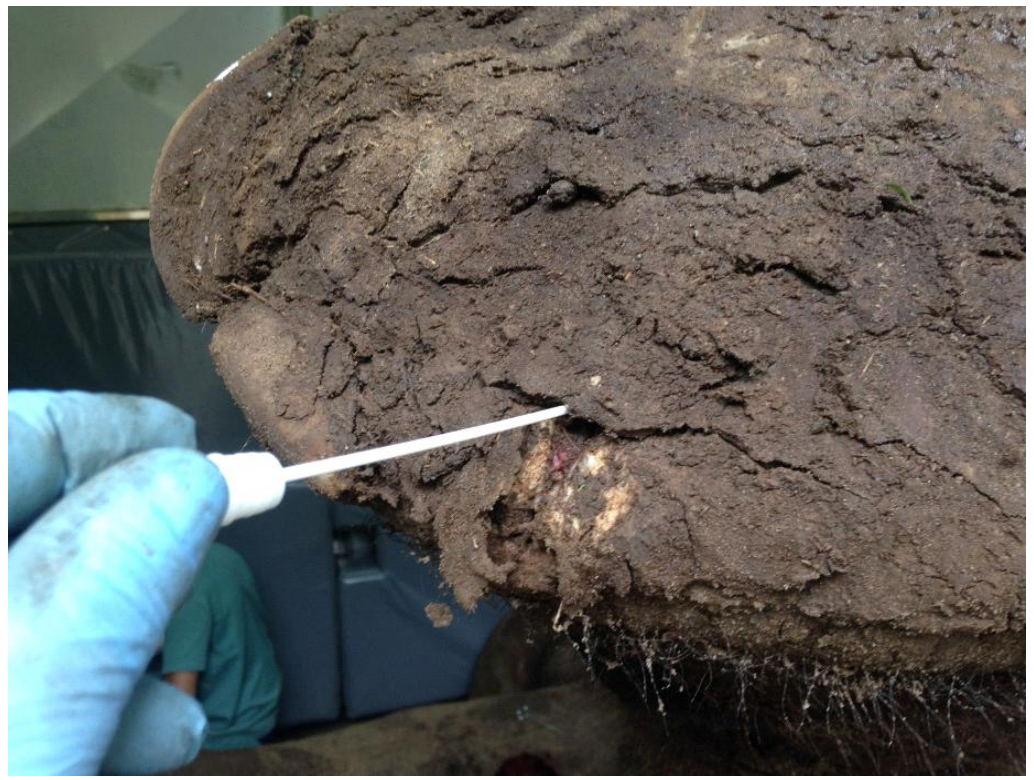

Figura 1. Coleta de material biológico da pata traseira de elefante asiático (E. maximus), com auxílio de swab estéril.

\section{RESULTADO E DISCUSSÃO}

Os exames laboratoriais revelaram o crescimento de bactérias do grupo das enterobactérias: Klebsiella $s p$ e Citrobacter $s p$ e o resultado do teste de sensibilidade microbiana apontou sensibilidade para quatro antibióticos em relação às bactérias isoladas: cefalexina, gentamicina, neomicina e sulfametoxazol-trimetoprim e sensibilidade intermediária para azitromicina. No resultado do antibiograma da bactéria Klebsiella $s p$, houve sensibilidade ao antibiótico amoxicilina + ácido clavulânico e sensibilidade intermediária para enrofloxacin, e no resultado do teste de sensibilidade da bactéria Citrobacter sp, houve uma inversão nos resultados, com sensibilidade ao antimicrobiano cefalexina e intermediário ao medicamento amoxicilina + ácido clavulônico (Tabela 1).

Tabela 1. Resultados do teste de sensibilidade frente aos antimicrobianos testados

\begin{tabular}{|c|c|c|c|}
\hline \multicolumn{2}{|c|}{ Bactéria isolada (Klebsiella sp) } & \multicolumn{2}{|c|}{ Bactéria isolada (Citrobacter $s p$ ) } \\
\hline antibiótico & resultado & antibiótico & resultado \\
\hline Amoxicilina + ácido clavulânico & Sensível & Amoxicilina + ácido clavulânico & Intermediário \\
\hline Azitromicina & Intermediário & Azitromicina & Intermediário \\
\hline Cefalexina & Sensível & Cefalexina & Sensível \\
\hline Enrofloxacin & Intermediário & Enrofloxacin & Sensível \\
\hline Gentamicina & Sensível & Gentamicina & Sensível \\
\hline
\end{tabular}

Teixeira RHF. Pododermatite em elefante-asiático (Elephas maximus Linnaeus, 1758), mantido sob cuidados humanos Vet. e Zootec. 2021 ; v28: 001-005. 


\begin{tabular}{|l|l|l|l|}
\hline Neomicina & Sensível & Neomicina & Sensível \\
\hline Sulfametoxazol-trimetoprim & Sensível & Sulfametoxazol-trimetoprim & Sensível \\
\hline
\end{tabular}

A evolução do tratamento clínico está diretamente associada à índole e acesso ao paciente, ou seja, o animal deve aceitar o manejo, caso contrário pode apresentar sérios riscos aos médicos-veterinários e equipe. A recomendação do tratamento não difere dos demais animais com lesões podais: limpeza, curativos e uso de antibióticos tópicos e sistêmicos. Aliado ao tratamento é vital providenciar um substrato pouco abrasivo, constituído de areia fina e manter o local seco e limpo

Não se tem notícias de lesões podais em elefantes no ambiente natural, e certamente, em vida livre, os indivíduos acometidos com lesões em patas estão condenados à morte, uma vez que elefantes realizam longas jornadas em busca de alimento, água e abrigos. Os problemas podais em elefantes mantidos em ambientes artificiais são comuns devido a diversos fatores, mas principalmente ao excesso de peso do animal, substrato abrasivo e inapropriado, falta de higiene e contato com fezes e urina entre outros fatores.

O presente estudo conseguiu êxito no isolamento do agente microbiano, assim como, revelou resultados satisfatórios ao teste de sensibilidade microbiana. Mais estudos relacionados a problemas podais em elefantes mantidos sob cuidados humanos devem ser realizados, para se conhecer a relação entre as lesões podais e a presença de agentes infecciosos.

\section{AGRADECIMENTO}

Aos residentes e servidores do Zoológico.

\section{REFERENCIAS}

1. Choudhury A, Lahiri CDK, Desai A, Duckworth JW, Easa PS, Johnsingh AJT, et al. Elaphas maximus (IUCN) Asian elephant specialist group. Cambridge: IUCN Red List of Threatened $\quad$ Species; 2008. p. e.T7140A12828813. doi: 10.2305/IUCN.UK.2008.RLTS.T7140A12828813.

2. Associação de Zoológicos e Aquários do Brasil [Internet]. Sorocaba: AZAB; 2020 [citado 9 Dez 2020]. Disponível em: https://www.azab.org.br/home

3. Harris M, Sherwin C, Harris S. The welfare, housing and husbandry of elephants in United Kingdom zoologicals. Zoos Forum: Review of issues in elephant husbandry in UK zoos. Bristol: University of Bristol; 2008.

4. Haspeslagh M, Stevens J, Groot E, Dewulf J, Kalmar, I, Moons C. A survey of foot problems, stereotypic behaviour and floor type in Asian elephants (Elephas maximus) in European zoos. Anim Welf. 2013;22(4):437-43. doi: 10.7120/09627286.22.4.437.

5. Lewis KD, Shepherdson DJ, Owens TM, Keele M. A survey of elephant husbandry and foot health in North American zoos. Zoo Biol. 2010;29(2):221-36. doi: 10.1002/zoo.20291.

6. Miller MA, Hogan JN, Meehan CL. Housing and demographic risk factors impacting foot and musculoskeletal health in African elephants (Loxodonta africana) and Asian elephants (Elephas maximus) in North American zoos. Plos One. 2016;11(7):1-17. doi: 10.1371/journal.pone.0155223.

Teixeira RHF. Pododermatite em elefante-asiático (Elephas maximus Linnaeus, 1758), mantido sob cuidados humanos Vet. e Zootec. 2021 ; v28: 001-005. 
7. Paulin W, Ertl N, Flügger M, Sós E, Schiffmann C, Clauss M, et al. Foot health of asian elephants (Elephas maximus) in european zoos. J Zoo Wildl Med. 2019;50(3):513-27. doi: $10.1638 / 2018-0228$.

8. Edwards KL, Miller MA, Carlstead K, Brown JL. Relationships between housing and management factors and clinical health events in elephants in North American zoos. Plos One. 2019;14(6):2-12. doi: 10.1371/joiurnal.pone0217774.

9. Canton R, Morosini MI. Emergence and spread of antibiotic resistance following exposure to antibiotics. Microbiol Rev. 2011;35(5):997-1. doi: 10.1111/j.1574-6976.2011.00295.x.

10. Losch LS, Alonso JM, Merino LA. Occurrence of antimicrobial resistant Enterobactericeae in water from different sources in a subtropical regions of Argentina. Rev Ambient Agua. 2008;3(2):29-9. doi: 10.4136/ambi-agua.50.

11. Knöbl PV, Viveiros JF, Franco LS, Davies YM, Cunha MPV, Menão MC, et al. Identificação de Klebsiella spp. em fezes de psitacídeos cativos. Atas Saude Ambient. 2017;5(1):189-94.

Recebido em: 14/01/2021 Aceito em: 31/08/2021 